\title{
[Reseach Note] \\ Effects of Changes in Asphaltenes on Viscosity Reduction of Heavy Oil after Thermal Visbreaking
}

\author{
Yaorong CAI, Ruiming Wu, Yan SHI*, Xiaoqiang WANG, Zhiwei YAO, and Qingshan RoNG \\ College of Chemistry, Chemical Engineering and Environmental Engineering, Liaoning Shihua University, Fushun, 113001, P. R. CHINA
}

(Received January 25, 2018)

\begin{abstract}
Changes in asphaltene content in heavy oils after thermal visbreaking at different cracking temperatures and reaction times were studied by various techniques, including elemental analysis, X-ray diffraction, Fourier transform infrared spectroscopy and nuclear magnetic resonance spectroscopy. The yield of asphaltene decreased at the beginning of thermal visbreaking, but further increased with deep thermal visbreaking. The aromaticity of asphaltene increased with higher cracking severity. In addition, the effect of asphaltene on viscosity was investigated before and after thermal visbreaking. There was a close relationship between asphaltene content and viscosity, and the viscosity increased dramatically with higher asphaltene content. The viscosities were also different at the same asphaltene content due to the differences in chemical composition and macrostructure of the asphaltene molecules. Therefore, both the contents and structures of asphaltene had significant influences on the viscosity of heavy oils. However, the changes in the content and structure of asphaltene were not major causes for the decrease in viscosity after thermal visbreaking.
\end{abstract}

\section{Keywords}

Heavy oil, Asphaltene, Viscosity, Visbreaking

\section{Introduction}

Heavy oils are present in huge reserves with worldwide distribution, but have high viscosity greater than $0.1 \mathrm{~Pa} \mathrm{~s}^{1)}$, which limits both extraction and transportation. Various technologies have been applied to reduce the viscosity ${ }^{2) \sim 4)}$, including additives to the oil, heating of the oil, blending the oil with lighter oils or hydrocarbon gases, oil-in-water emulsification and microbial methods. Thermal visbreaking has also been widely applied because of the lower capital and operation costs.

Thermal visbreaking is a mild form of thermal cracking in which the viscosity of the heavy oils is permanently decreased by the cleavage of $\mathrm{C}-\mathrm{C}$ bonds and the opening of ring structures to form a larger number of molecules with lower viscosity. Previous studies of thermal visbreaking have focused on the visbreaking process, changes in the physical and chemical properties of cracked products $^{5)}$, reaction pathways or kinetics ${ }^{6), 7)}$. The effect of the fractions from cracked products has not been widely reported. Additionally, the presence of asphaltene is important in the high viscosity of heavy oil. Asphaltene is generally recognized to cause higher

DOI: doi.org/10.1627/jpi.62.74

* To whom correspondence should be addressed.

* E-mail: shiyan1816@163.com viscosity in different fractions, which originates from the specific properties dependent on the formation of intermolecular aggregates with other hydrocarbons ${ }^{1,, 8) \sim 10)}$. Therefore, the effect of asphaltene on viscosity should be understood.

This study investigated the changes in asphaltenes after thermal visbreaking using various methods, including elemental analysis, X-ray diffraction (XRD), Fourier transform infrared (FT-IR) spectroscopy and nuclear magnetic resonance (NMR). In addition, oil samples were prepared by diluting the asphaltene fraction into $n$-heptane deasphalted oils and determining their viscosity. Finally, the involvement of asphaltene in the decrease of viscosity after visbreaking and the effects of asphaltene on the viscosity of heavy oils were evaluated.

\section{Experimental}

\section{1. Materials}

Experimental heavy oil samples were obtained from MRE-2, Venezuela, and used as the feedstock for thermal visbreaking. Samples were separated into $n$-heptane asphaltenes (MREAP) and $n$-heptane deasphalted oils (DAO). The properties of the feedstocks are shown in Table 1. All experimental samples were stirred to ensure homogeneous samples. Other materials included $n$-heptane $(97 \%)$ and toluene $(97 \%)$ supplied by 
Table 1 Properties of MRE-2 Crude Oil

\begin{tabular}{lrc}
\hline \multicolumn{1}{c}{ Properties } & Value \\
\hline$\rho^{25.1^{\circ} \mathrm{C}}$ & {$\left[\mathrm{kg} / \mathrm{m}^{3}\right]$} & 975 \\
$\mu$ & {$\left[\mathrm{mPa} \mathrm{s}, 25^{\circ} \mathrm{C}\right]$} & 8775 \\
Elemental analysis & {$[\mathrm{wt} \%]$} & \\
$\mathrm{C}$ & & 82.75 \\
$\mathrm{H}$ & & 13.60 \\
$\mathrm{~N}$ & 0.53 \\
$\mathrm{~S}$ & & 3.62 \\
SARA content & {$[\mathrm{wt} \%]$} & \\
Saturates & 28.7 \\
Aromatics & & 30.3 \\
Resins & 30.8 \\
N-C ${ }_{7}$ Asphaltenes & 10.3 \\
\hline
\end{tabular}

\begin{tabular}{cc}
\hline Distillation [vol\%] & $T\left[{ }^{\circ} \mathrm{C}\right]$ \\
\hline 0 & 172 \\
5 & 279 \\
10 & 302 \\
20 & 370 \\
30 & 439 \\
40 & 498 \\
50 & 567 \\
60 & 619 \\
\hline
\end{tabular}

30.8

10.3

Sinopharm Chemical Reagent Co., Ltd.

\section{2. Preparation of Asphaltene and Reconstituted} Oil Samples

The thermal visbreaking experiments were conducted at three cracking temperatures $\left(370,390\right.$, and $\left.410{ }^{\circ} \mathrm{C}\right)$ and three reaction times $(30,50$, and $60 \mathrm{~min})$ in a stainless steel reactor. The liquid products were collected and the cracked oils were separated into asphaltene and deasphalted oil according to ASTM D4124. The asphaltenes were specified as 370/30AP, 370/60AP, 370/90AP, 390/30AP, and so on. Then, the reconstituted oil samples were prepared by diluting asphaltene into the DAO. Firstly, to study the relationship between asphaltene content and viscosity, six reconstituted oil samples containing different asphaltene mass fractions of $2.5,5.0,7.5,10.0,12.5$ and $15.0 \mathrm{wt} \%$ were prepared with DAO. Secondly, to investigate the effect of cracked asphaltene on the viscosity of heavy oil, ten reconstituted oil samples containing constant asphaltene mass fraction $(10.0 \mathrm{wt} \%)$ were prepared. For example, the sample of $37 / 3 \mathrm{AO}$ was prepared by diluting 370/30AP into DAO. The viscosities of these reconstituted oil samples were determined at different temperatures (sheer rate from 1 to $200 \mathrm{~s}^{-1}$ ).

\section{3. Characterization of Asphaltenes}

Elemental analysis of the asphaltenes was carried out with a Vario MICRO CUBE analyzer to determine the carbon, hydrogen, nitrogen, and sulfur contents. The oxygen content was calculated by subtracting the $\mathrm{C}, \mathrm{H}$, $\mathrm{N}$, and $\mathrm{S}$ contents from $100 \%$.

XRD analysis was carried out with a D-max-RB instrument using $30 \mathrm{kV}$ voltages and $15 \mathrm{~mA}$ current, using $\mathrm{CuK} \alpha\left(1.5405 \AA, 1 \AA=10^{-10} \mathrm{~m}\right)$ monochromic energy radiation. A NaI detector (scintillation detector) was used to collect the diffraction signals. The diffraction angle $(2 \theta)$ was scanned from 11 to $70^{\circ}$ at $1^{\circ} / \mathrm{min}$ scan rate with a $0.05^{\circ}$ step size. According to the XRD patterns with curve de-convolution for asphaltenes (Fig. 1), the aromaticity $\left(f_{\mathrm{a}}\right)$ and the average height $\left(L_{\mathrm{c}}\right)$ of the stack of the aromatic sheet were calculated from the following equations ${ }^{5}$ :
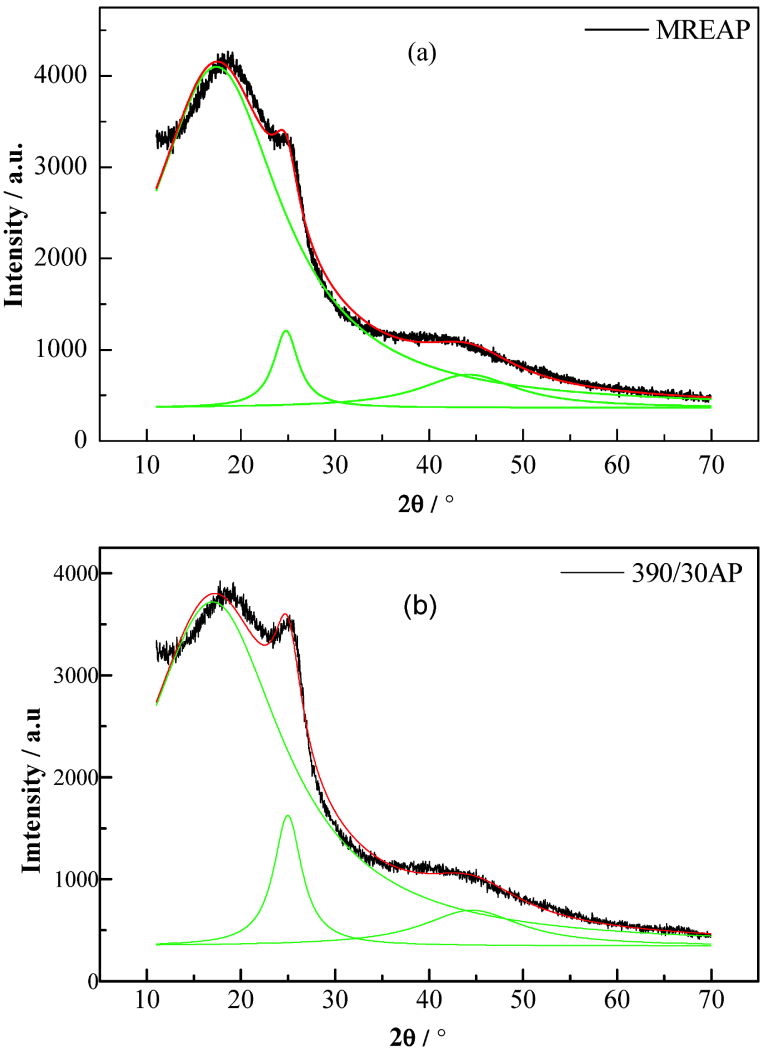

Fig. 1 XRD Pattern of Asphaltene

$$
f_{\mathrm{a}}=\frac{A_{(\text {graphene })}}{A_{(\text {graphene })}+A_{(\gamma)}}
$$

In Eq. (1), $A_{\text {(graphene) }}$ and $A_{(\gamma)}$ are the areas of resolved peaks for the graphene and $\gamma$ bands, respectively.

$$
L_{\mathrm{c}}=0.9 \omega \cos \theta_{002 \text {-band }}
$$

In Eq. (2), $\theta_{002}$-band and $\omega$ are the Bragg's angle at which the peak of (002) band is centered and the bandwidth, respectively.

The changes in asphaltene after thermal visbreaking were investigated by Fourier transition infrared (FT-IR) 


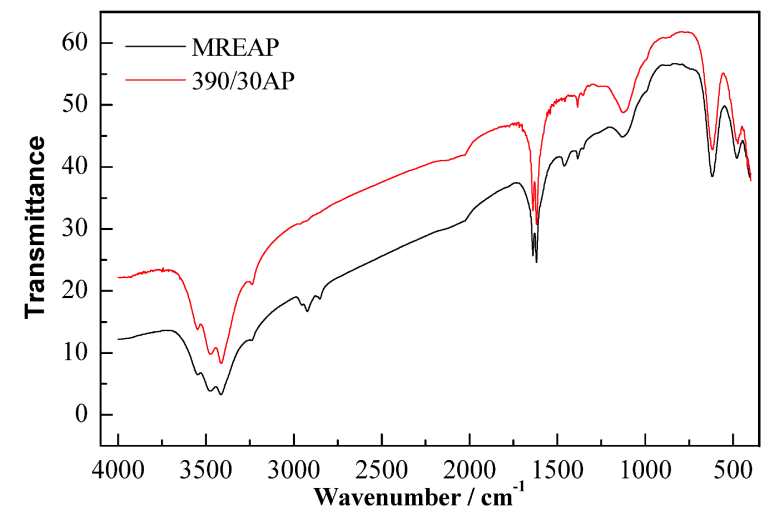

Fig. 2 FT-IR Spectra of Asphaltene

spectrometry (Perkin-Elmer USA). The spectra was recorded in the range of $400-4000 \mathrm{~cm}^{-1}$, with a resolution of $0.482 \mathrm{~cm}^{-1}$. The FT-IR spectrum of asphaltene sample is shown in Fig. 2. The peak areas $A_{1}, A_{2}$ and $A_{3}$ were calculated by computer software, which corresponded to the aliphatic $\mathrm{CH}\left(3000-2800 \mathrm{~cm}^{-1}\right)$, carbonyl $\mathrm{C}=\mathrm{O}\left(1770-1650 \mathrm{~cm}^{-1}\right)$ and aromatic $\mathrm{C}=\mathrm{C}(1650$ $\left.1550 \mathrm{~cm}^{-1}\right)$ stretching absorption regions respectively ${ }^{11)}$.

The carbon aromaticities of asphaltene were determined with a $300 \mathrm{MHz}$ NMR spectrometer (Mercury-300, Varian, USA). Asphaltene samples were dissolved into deuterated chloroform $\left(\mathrm{CDCl}_{3}\right)$ and the NMR spectrometer was preset with a pulse flip angle of $30^{\circ}$, sampling tube diameter of $5 \mathrm{~mm}$, and spectral width of $15 \mathrm{ppm}$ and $235 \mathrm{ppm}$ for measuring the ${ }^{1} \mathrm{H}$ NMR spectra and ${ }^{13} \mathrm{C}$ NMR spectra, respectively. Intensity after the integration process was used for the calculation of aromaticity. According to ASTM D5292-99, the aromaticity, $f_{\mathrm{a}}$, of the asphaltene sample was calculated as follows:

$$
f_{\mathrm{a}}=\frac{A}{A+B}
$$

$A$ and $B$ refer to the integrals for the aromatic hydrogen band (5.0-10.0 ppm region) and aliphatic hydrogen band (0.3-5.0 ppm region) from ${ }^{1} \mathrm{H}$ NMR spectra and ${ }^{13} \mathrm{C}$ NMR spectra, respectively. For the aromatic hydrogen content, $A$ and $B$ are equal to the integrals for the aromatic hydrogen band (5.0-10.0 ppm region) and aliphatic hydrogen band ( $-0.5-5.0 \mathrm{ppm}$ region), respectively. For the aromatic carbon content, $A$ and $B$ are equal to the integrals for the aromatic carbon band (100-170 ppm region) and aliphatic carbon band ( -10 $70 \mathrm{ppm}$ region), respectively. Sample ${ }^{1} \mathrm{H}$ and ${ }^{13} \mathrm{C}$ NMR spectra of MREAP are presented in Figs. 3 and $\mathbf{4}$, respectively.

\section{Results and Discussion}

\section{1. Changes in Asphaltene}

The elemental compositions and contents of asphal-

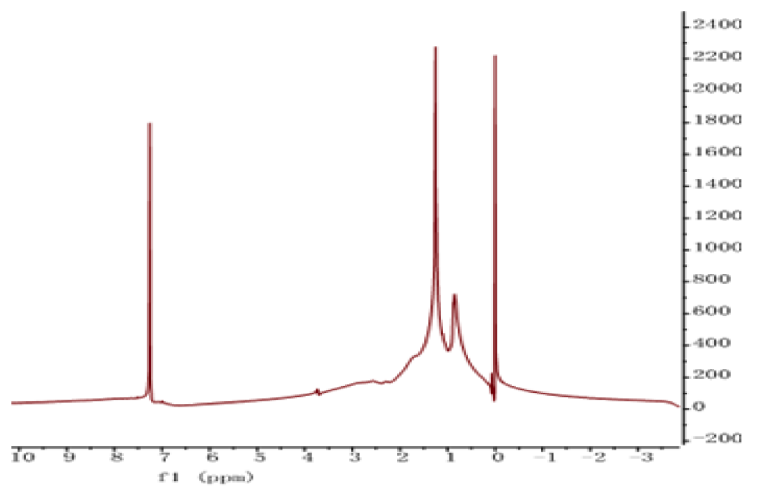

(a)

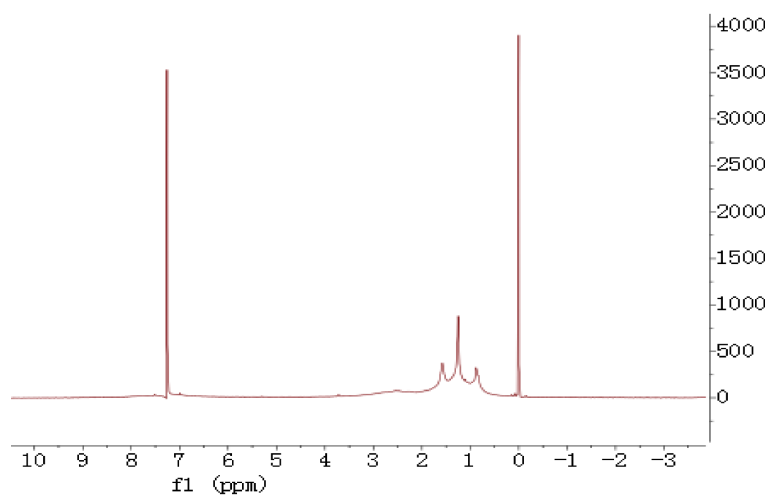

(b)

Fig. $3{ }^{1} \mathrm{H}$ NMR Spectra of MREAP (a) and 390/30AP (b)

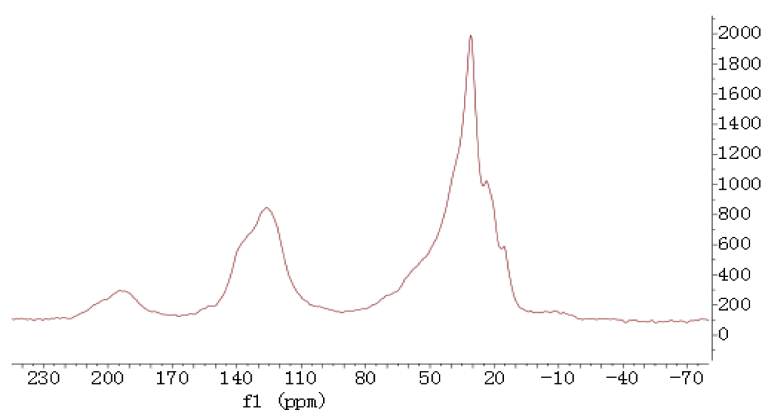

(a)

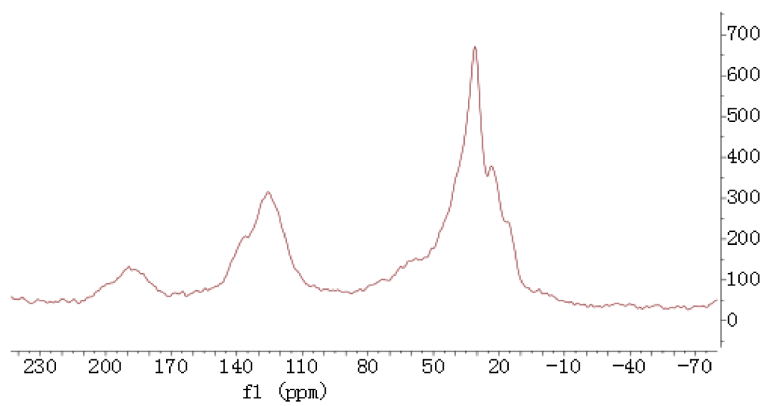

(b)

Fig. $4{ }^{13}$ C NMR Spectra of MREAP (a) and 390/30AP (b) 
Table 2 Elemental Composition and Yield of Asphaltene

\begin{tabular}{|c|c|c|c|c|c|c|c|c|c|c|}
\hline & \multirow{2}{*}{ MREAP } & \multicolumn{3}{|c|}{370} & \multicolumn{3}{|c|}{390} & \multicolumn{3}{|c|}{410} \\
\hline & & 30 & 60 & 90 & 30 & 60 & 90 & 30 & 60 & 90 \\
\hline Yield [\%] & 10.5 & 9.8 & 10.2 & 11.9 & 9.6 & 10.8 & 12.3 & 9.7 & 11.5 & 13.2 \\
\hline \multicolumn{11}{|c|}{ Element content $[\%]$} \\
\hline $\mathrm{C}$ & 81.5 & 83.2 & 84.2 & 85.0 & 83.8 & 84.8 & 85.3 & 84.0 & 85.0 & 85.5 \\
\hline $\mathrm{H}$ & 9.4 & 9.0 & 8.8 & 8.7 & 8.9 & 8.8 & 8.6 & 8.7 & 8.6 & 8.5 \\
\hline $\mathrm{O}$ (differ.) & 2.0 & 1.0 & 1.8 & 1.1 & 1.5 & 1.4 & 1.4 & 1.0 & 1.2 & 1.0 \\
\hline $\mathrm{N}$ & 2.6 & 2.5 & 2.0 & 1.6 & 1.9 & 1.8 & 1.5 & 2.6 & 1.8 & 1.7 \\
\hline S & 4.5 & 4.3 & 3.8 & 3.6 & 3.9 & 3.5 & 3.2 & 3.7 & 3.4 & 3.3 \\
\hline
\end{tabular}

Table 3 Aromaticity $\left(f_{\mathrm{a}}\right)$ and Average Height $\left(L_{\mathrm{c}}\right)$ of the Stack of the Aromatic Sheet from XRD

\begin{tabular}{lcccccc}
\hline Asphaltene & MREAP & $370 / 30 \mathrm{AP}$ & $370 / 60 \mathrm{AP}$ & $370 / 90 \mathrm{AP}$ & $390 / 30 \mathrm{AP}$ \\
\hline$f_{\mathrm{a}}$ & & 0.01 & 0.01 & 0.02 & 0.03 & 0.03 \\
$L_{\mathrm{c}}$ & {$[\AA]$} & 21.5 & 23.8 & 20.7 & 15.4 & 22.8 \\
\hline \multicolumn{2}{l}{ Asphaltene } & $390 / 60 \mathrm{AP}$ & $390 / 90 \mathrm{AP}$ & $410 / 30 \mathrm{AP}$ & $410 / 60 \mathrm{AP}$ & $410 / 90 \mathrm{AP}$ \\
\hline \multicolumn{2}{l}{$f_{\mathrm{a}}$} & 0.04 & 0.08 & 0.05 & 0.07 & 0.09 \\
$L_{\mathrm{c}}$ & {$[\AA]$} & 20.3 & 19.9 & 22.2 & 19.5 & 18.8 \\
\hline
\end{tabular}

Table 4 Aromaticity $\left(f_{\mathrm{a}}\right)$ of Asphaltene from NMR Analysis

\begin{tabular}{cccccc}
\hline Asphaltene & MREAP & $370 / 30 \mathrm{AP}$ & $370 / 60 \mathrm{AP}$ & $370 / 90 \mathrm{AP}$ & $390 / 30 \mathrm{AP}$ \\
\hline${ }^{1} \mathrm{H}$ aromaticity & 0.16 & 0.17 & 0.18 & 0.20 & 0.19 \\
${ }^{13} \mathrm{C}$ aromaticity & 0.35 & 0.36 & 0.36 & 0.38 & 0.36 \\
\hline Asphaltene & $390 / 60 \mathrm{AP}$ & $390 / 90 \mathrm{AP}$ & $410 / 30 \mathrm{AP}$ & $410 / 60 \mathrm{AP}$ & $410 / 90 \mathrm{AP}$ \\
\hline${ }^{1} \mathrm{H}$ aromaticity & 0.19 & 0.21 & 0.18 & 0.20 & 0.22 \\
${ }^{13} \mathrm{C}$ aromaticity & 0.37 & 0.39 & 0.36 & 0.37 & 0.40 \\
\hline
\end{tabular}

tene in MRE-2 and cracked products are shown in Table 2. Clearly the yield of asphaltene decreases at the beginning of thermal visbreaking due to the breaking of the weak bonds between alkyl groups and the poly-aromatic base unit. Subsequently, the yield of asphaltene increases with deep thermal visbreaking because the asphaltenes and maltenes undergo other reaction pathways, such as dehydrogenation, aromatization of naphthenic groups, condensation or pericondensation of aromatic rings, and so on. In addition, the content of $\mathrm{C}$ increased but the content of $\mathrm{H}$ decreased with deep thermal visbreaking. The changes of content of other elements are difficult to determine. The results indicate that the aromaticity of asphaltene increases with higher cracking severity.

XRD analyses of the changes in aromaticity $\left(f_{\mathrm{a}}\right)$ and average height $\left(L_{\mathrm{c}}\right)$ of the stack of the aromatic sheet are shown in Table 3. Aromaticity $\left(f_{\mathrm{a}}\right)$ increased but average height $\left(L_{\mathrm{c}}\right)$ of the stack of the aromatic sheet decreased with higher temperature and longer reaction time. The aromaticity $\left(f_{\mathrm{a}}\right)$ and the average height $\left(L_{\mathrm{c}}\right)$ of the stack of the aromatic sheet are dependent on the severity of thermal visbreaking ${ }^{5)}$.

NMR analyses of the ${ }^{1} \mathrm{H}$ and ${ }^{13} \mathrm{C}$ aromaticity $\left(f_{\mathrm{a}}\right)$ of various asphaltenes are shown in Table $4 . \quad{ }^{1} \mathrm{H}$ and ${ }^{13} \mathrm{C}$ aromaticity $\left(f_{\mathrm{a}}\right)$ depended on the reaction temperature and time in agreement with the XRD findings. However, the values from XRD are smaller than from NMR because the calculation of aromaticity $\left(f_{\mathrm{a}}\right)$ from the XRD spectra is based only on the stack cluster aromatic carbon which contributes to the graphene peak rather than all aromatic carbon in the asphaltene.

The $A_{3} / A_{1}$ (degree of aromaticity in the molecular matrix) and the $A_{2} / A_{3}$ ratio (degree of carbonyl concentration per unit of aromatic structures) were considered $^{11)}$ as listed in Table 5. The $A_{3} / A_{1}$ and $A_{2} / A_{3}$ ratios displayed complex trends due to the asphaltenes undergoing primary and secondary reactions.

\section{2. Variation in Viscosity after Visbreaking}

The viscosities of thermal visbreaking products are compared in Fig. 5. The viscosity of cracked oil decreased with longer reaction time and higher reaction temperature. The decrease in viscosity is ascribed to the changes in the chemical composition of the oil after thermal treatment.

\section{3. Viscosity and Asphaltene}

The relationship between viscosity and asphaltene content at different temperatures is shown in Fig. 6. 
Table 5 Changes Aromaticity in the Molecular Matrix $\left(A_{3} / A_{1}\right)$ and Carbonyl Concentration per Unit of Aromatic Structures $\left(A_{2} / A_{3}\right)$

\begin{tabular}{|c|c|c|c|c|c|}
\hline Asphaltene & MREAP & 370/30AP & 370/60AP & 370/90AP & 390/30AP \\
\hline$A_{3} / A_{1}$ & 0.14 & 0.17 & 0.10 & 0.18 & 0.20 \\
\hline$A_{2} / A_{3}$ & 0.21 & 0.28 & 0.89 & 0.12 & 0.20 \\
\hline Asphaltene & 390/60AP & 390/90AP & 410/30AP & 410/60AP & 410/90AP \\
\hline$A_{3} / A_{1}$ & 0.13 & 0.13 & 0.16 & 0.08 & - \\
\hline$A_{2} / A_{3}$ & 0.52 & 0.39 & 0.47 & 1.01 & 1.01 \\
\hline
\end{tabular}

Table 6 Effect of Cracked Asphaltene on Viscosity of Heavy Oil

\begin{tabular}{lccccc}
\hline Oil sample $($ asphaltene content $=10 \mathrm{wt} \%)$ & MREAO & $37 / 3 \mathrm{AO}$ & $37 / 6 \mathrm{AO}$ & $37 / 9 \mathrm{AO}$ & $39 / 3 \mathrm{AO}$ \\
\hline Viscosity $\left[\mathrm{mPa} \mathrm{s}, 25^{\circ} \mathrm{C}\right]$ & 7665 & 10001 & 19472 & 18972 & 13645 \\
\hline Oil sample & $39 / 6 \mathrm{AO}$ & $39 / 9 \mathrm{AO}$ & $41 / 3 \mathrm{AO}$ & $41 / 6 \mathrm{AO}$ & $41 / 9 \mathrm{AO}$ \\
\hline Viscosity $\left[\mathrm{mPa} \mathrm{s}, 25^{\circ} \mathrm{C}\right]$ & 11134 & 18140 & 14598 & 15318 & 25872 \\
\hline
\end{tabular}

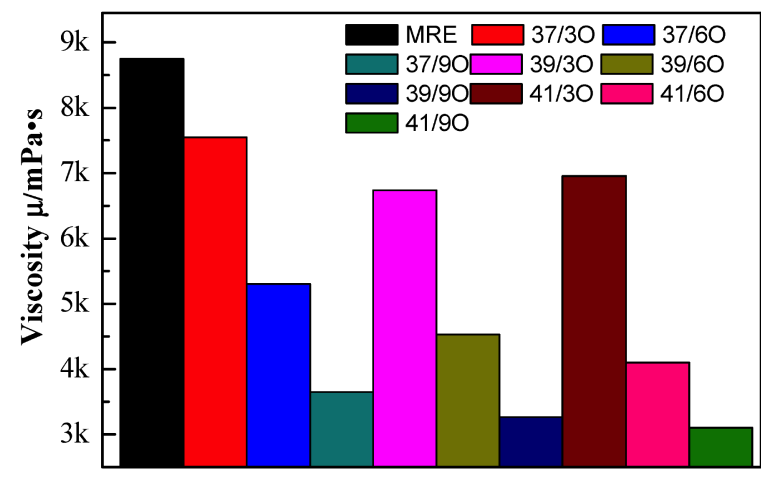

MREO refers to feedstock, and others refer to the products of thermal visbreaking, such as $390 / 30$ (products of visbreaking at $390{ }^{\circ} \mathrm{C}$ for $30 \mathrm{~min})$.

Fig. 5 Changes in Product Viscosity at $25^{\circ} \mathrm{C}$ after Thermal Visbreaking

The viscosity of reconstituted oil increased with higher asphaltene content at constant temperature (especially at $25^{\circ} \mathrm{C}$ ). However, a critical mass fraction (about $10 \mathrm{wt} \%$ ) of asphaltene existed between asphaltene content and viscosity of reconstituted oils. Asphaltene content is above $10 \mathrm{wt} \%$ resulted in dramatically increased viscosity due to the agglomeration of asphaltene particles and strong inter-particle interactions between these asphaltene particles.

The effects of cracked asphaltene on viscosity of heavy oil are compared in Table 6. The viscosity of cracked asphaltene reconstituted oil samples was higher than that of MREAO at $25^{\circ} \mathrm{C}$, and the change in viscosity of reconstituted heavy oil sample showed no trend. According to present suspension viscosity theories, the volume fraction and aggregation state of asphaltene particles in any heavy oil sample can greatly affect its viscosity. The unstable changes in viscosity result from the complex reactions of asphaltene, including

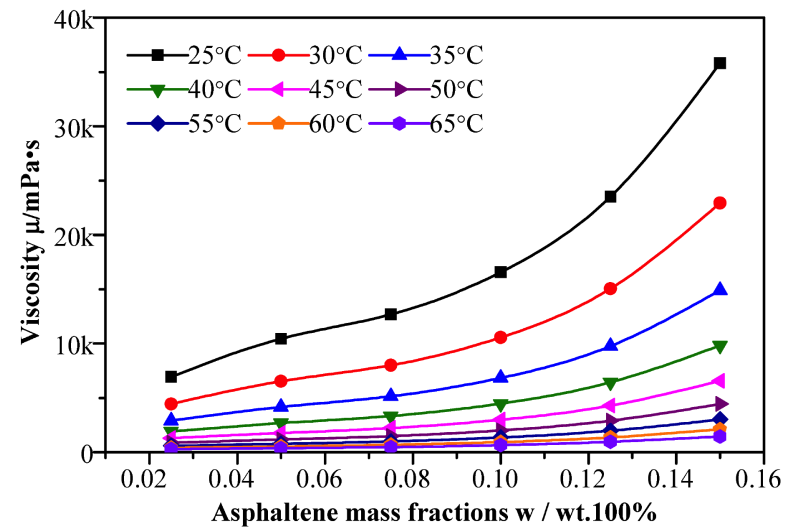

Fig. 6 Relationship between Asphaltene Content and Viscosity

dealkylation of side aliphatic chains, cyclization of alkyl chains, and combination of ring radicals by polymerization, dehydrogenation and aromatization of naphthenic rings, and condensation and pericondensation of aromatic rings.

\section{Conclusion}

The effects of the content and structure of asphaltene on the viscosity of heavy oil were investigated. The structure of asphaltene was characterized by elemental analysis, XRD, NMR and FT-IR. The structure and contents of aspaltene were changed by thermal visbreaking, and were significant in the changes in viscosity, but not the major reason for viscosity reduction.

\section{Acknowledgment}

The work was supported by the National Natural Science Foundation of China (No. 21276253 and No. 21476101). 


\section{References}

1) Padula, L., Rocha, N. D. O., Harry Westfahl, J., Cardoso, M. B., Sabadini, E., Loh, W., Energy \& Fuels, 30, 3644 (2016).

2) Lu, H., Guan, X., Wang, B., Huang, Z., J. Surfactants Deterg., 18, 773 (2015).

3) Al-Hashmi, A. R., Al-Wahaibi, T. K., Al-Wahaibi, Y. M., Mjalli, F., Al-Omairi, R., J. Petrol. Explor. Prod. Technol., 7, 881 (2016).

4) Lavania, M., Cheema, S., Lal, B., Fuel, 144, 349 (2015).

5) Alhumaidan, F. S., Hauser, A., Rana, M. S., Lababidi, H. M. S., Behbehani, M., Fuel, 150, 558 (2015).
6) Sadighi, S., Seif, M., J. Petroleum Gas Eng., 4, 81 (2013).

7) Taghipour, A., Naderifar, A., Energy Technol., 3, 758 (2015).

8) Ilyin, S., Arinina, M., Polyakova, M., Bondarenko, G., Konstantinov, I., Kulichikhin, V., Malkin, A., J. Petrol. Sci. Eng., 147, 211 (2016).

9) Acevedo, S., Escobar, G., Gutiérrez, L. B., Rivas, H., Gutiérrez, X., Colloid. Surface. A, 71, 65 (2015).

10) Stratiev, D., Shishkova, I., Tsaneva, T., Mitkova, M., Yordanov, D., Fuel, 170, 115 (2016).

11) Daaou, M., Larbi, A., Martínez-Haya, B., Rogalski, M., J. Petrol. Sci. Eng., 138, 50 (2016). 